\title{
Extensible Markup Language
}

National Cancer Institute

\section{Source}

National Cancer Institute. Extensible Markup Language. NCI Thesaurus. Code C45967.

A general-purpose markup language for creating special-purpose markup languages. It is capable of describing many different kinds of data. Its primary purpose is to facilitate the sharing of data across different systems, particularly systems connected via the Internet. 